Faculdade de Ciências Econômicas UFRGS
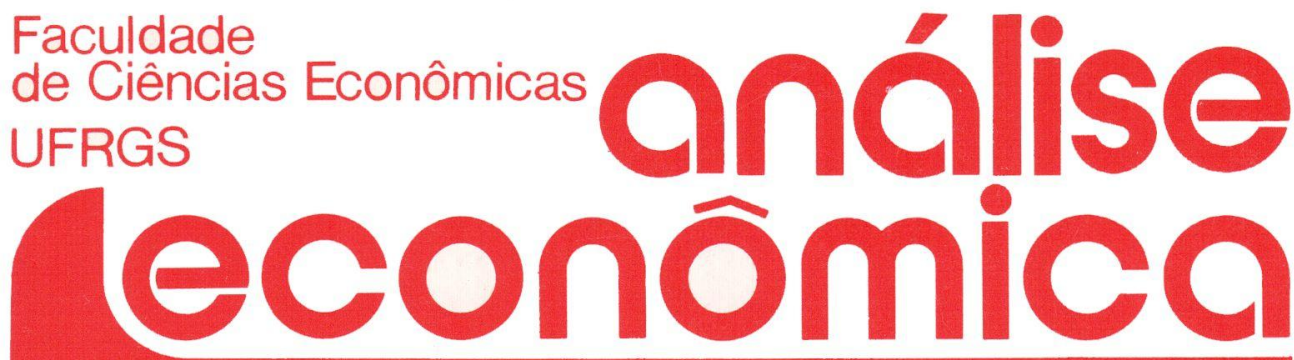

- apResentaÇ̃o à "ANálise simples da MAXIMIZAÇÂO DO BEM-ESTAR" DE FRANCIS BATOR

João Rogério Sanson

- UMA ANÁlise SIMPLES da MAXIMIZAÇÃo do BEM-ESTAR

Francis M. Bator

- O Regime de câmbio flutuante numa ETAPA DE TRANSICÃO

Francisco Eduardo Pires de Souza

- AgREgAdos monetÁRIOS, NIVEL DE RENDDA NOMINAL, TAXA DE INFLAÇÃO: UMA ANÁLISE DA CAUSALIDADE NO BRASIL, 1972 A 1987

Divanildo Triches

- A EXPlosão de CONSUMO do CRUzAdo Marcelo Cortes Neri

- METOdologia de PLANEJAMENTO do SETOR ELÉTRICO: QUESTŐES DOS ANOS 90

João Lizarolo de Araújo

Adilson de Oliveira

- CONCENTRAÇÃo INDUSTRIAL NO BRASIL SEGUNDO OS CENSOS, 1907-1980

Olimpio J. de Arrouxelas Galvão

- O VAlor, A RIQUEza e A TEORIA DE SMITH Reinaldo A. Carcanholo

- O "ESTADO ESTACIONÁRIO" e A ECONOMIa CLÁSSICA

Gentil Corazza

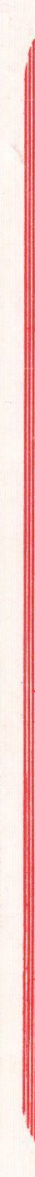
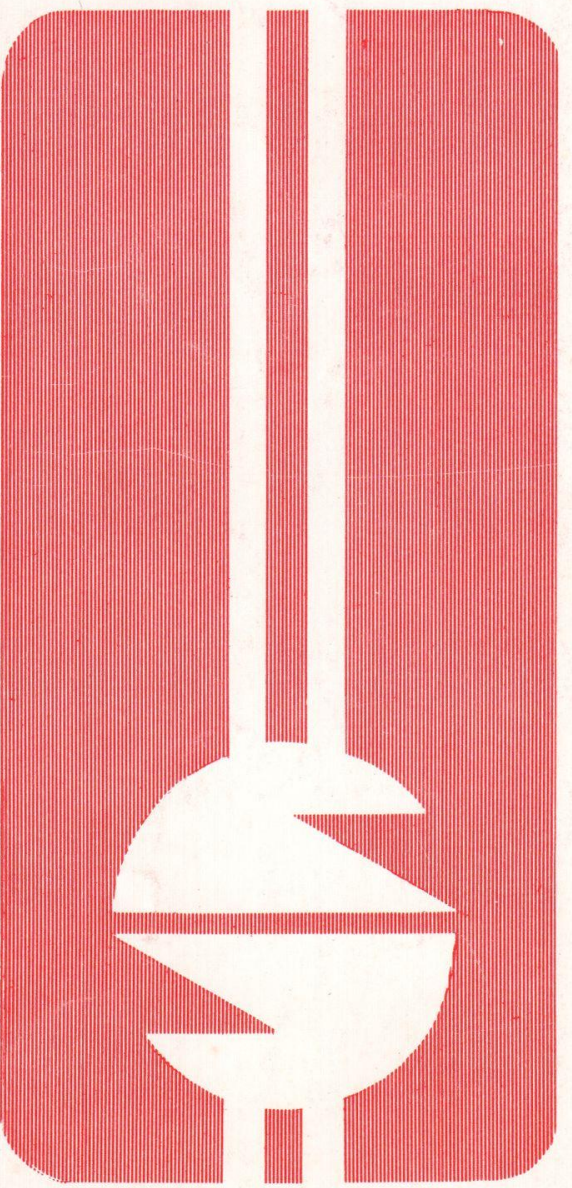
UNIVERSIDADE FEDERAL DO RIO GRANDE DO SUL

Reitor: Prof Tuiskon Dick

FACULDADE DE CIÊNCIAS ECONÔMICAS

Diretora: Prof ${ }^{\text {a }}$ Yeda Rorato Crusius

CENTRO DE ESTUDOS E PESQUISAS ECONÔMICAS

Diretor: Reinaldo Ignacio Adams

DEPARTAMENTO DE CIÊNCIAS ECONÔMICAS

Chefe: Prof. Pedro Cezar Dutra Fonseca

CURSO DE PÓS-GRADUAÇĀO EM ECONÔMIA

Coordenador: Prof. Nali de Jesus de Souza

CURSO DE PÓS-GRADUAÇĀO EM ECONOMIA RURAL

Coordenador: Prof. Atos Freitas Grawunder

CONSELHO EDITORIAL: Achyles Barcelos da Costa, Aray Miguel Feldens, Atos Freitas Grawunder, Carlos Augusto Crusius, Ernani Hickmann, João Rogério Sanson, Juvir Luiz Mattuella, Maria Imilda da Costa e Silva, Nali de Jesus de Souza, Nuno Renan Lopes de Figueiredo Pinto, Otilia Beatriz Kroeff Carrion, Otto Guilherme Konzen, Paulo Alexandre Spohr, Pedro Cezar Dutra Fonseca, Reinaldo Ignacio Adams, Roberto Camps Moraes, Valter José Stülp, Yeda Rorato Crusius, David Garlow (Wharton Econometrics Forecasts Association, E.U.A.), Edgar Augusto Lanzer (UFSC), Eleutério F. S. Prado (USP), Fernando Holanda Barbosa (FGV/RJ), Gustavo Franco (PUC/RJ), Joaquim Pinto de Andrade (UNB), Juan H. Moldau (USP), Werner Baer (Univ. de Illinois, E.U.A.)

COMISSÃO EDITORIAL: Atos Freitas Grawunder, Pedro Cezar Dutra Fonseca, Reinaldo Ignacio Adams e Roberto Camps Moraes.

EDITOR: Nali de Jesus de Souza

SECRETARIA: Maria Ivone de Mello (normalização), Vanete Ricacheski (revisão de textos), Zélide Bregalda (Secretária)

FUNDADOR: Prof. Antônio Carlos Santos Rosa

Os materiais publicados na revista Análise Econômica são de exclusiva responsabilidade dos autores. $\dot{E}$ permitida a reprodução total ou parcial dos trabalhos, desde que seja citada a fonte.

Aceita-se permuta com revista congêneres. Aceitam-se, também, livros para divulgação, elaboração de resenhas ou recensões.

Toda correspondência, material para publicaçāo (vide normas na $3^{\mathrm{a}}$ capa), assinaturas e permutas devem ser dirigidos ao seguinte destinatário:

PROF. NALI DE JESUS DE SOUZA

Revista Análise Econômica

Av. João Pessoa, 52

90.040 - PORTO ALEGRE (RS), BRASIL

Telefones: (0512) 28.1633; 24.6022; 26.0012 - Ramals 3440 e 3507

FAX: (0512) 25.5253 


\section{O "ESTADO ESTACIONÁRIO" \\ NA ECONOMIA CLÁSSICA}

Gentil Corazza*

\section{SINOPSE}

Este artigo pretende analisar a idéia de "Estado Estacionário" no åmbito da economia clássica, particularmente na obra de Smith, Ricardo e Stuart Mill. Estes autores centraram sua atenção na questão do crescimento econômico a longo prazo e na possibilidade, sempre presente, de que este crescimento venha a se interromper. 0 "Estado Estacionário" decorre da própria lógica da concepçåo clássica do crescimento: o estado progressivo desemboca, necessariamente, no "Estado Estacionário".

\section{INTRODUÇÃO}

Uma das preocupações centrais dos economistas clássicos, como Smith, Malthus, Ricardo e Stuart Mill, foi, sem dúvida, a questão do crescimento econômico a longo prazo. Nesse sentido, procuraram não só indicar os fatores propulsores do crescimento, como a divisão e a produtividade do trabalho, as inovaçōes técnicas e a crescente acumulação do excedente econômico, mas também procuraram conferir-lhe um estatuto teórico relevante. Ou seja, para eles, o crescimento da economia estava associado à contínua geração de um valor excedente, à forma de sua distribuição entre as classes sociais e à sua crescente acumulação.

Por outro lado, junto à preocupação com o crescimento a longo prazo, os pensadores clássicos sempre manifestaram uma outra, não menos importante, que diz respeito à possibilidade de interrupção desse mesmo crescimento. Perpassa toda a obra destes grandes autores, a idéia de que o crescimento não pode estender-se indefinidamente, ele tem um fim. No horizonte do crescimento, sempre aparece a idéia de

* Professor Assistente do Departamento de Ciências Económicas da UFRGS.

ANÁLISE ECONÓMICA

ANO 9 № 15

MARÇO/91

p.207-221 
que o caráter progressivo da economia devia desembocar num Estado estacionário. Esta idéia de que o mecanismo econômico apresenta defeitos, de que é movido por elementos internos que se auto-alimentam e também se desgastam, perdem capacidade de estimular o progresso, enfim, a idéia de estagnação, que se encontra latente em Smith e Ricardo, assume toda a sua forma em Stuart Mill.

Ao mesmo tempo em que os autores clássicos procuram descobrir as leis do crescimento, indicando seus fatores e sua articulação dinâmica, não é menor nos mesmos o esforço no sentido de eliminar seus obstáculos, bem como de indicar políticas favoráveis a esse crescimento. É importante notar que o principal obstáculo que debilita o processo de crescimento brota do interior mesmo da acumulação de capital. Ou seja, a acumulação caminha para um ponto de saturação. Isto é perfeitamente claro em Mill, mas se constitui também na questão central, embora não de forma tão explícita, já em Smith e Ricardo. Nestes dois autores existe a idéia de que um "excesso" de capital levaria a uma queda dos lucros e, por conseqüência, a um desestímulo ao prosseguimento da acumulação e ao Estado estacionário. Já, em Mill, fica perfeitamente claro que o advento do Estado estacionário coincide com o movimento de saturaçäo de capitàl.

A diferença entre Smith e Ricardo, de um lado, e Mill, de outro, não diz respeito apenas áo espaço teórico que dedicaram ao tema. A mais importante se refere à própria natureza atribuida ao Estado estacionácio. Enquanto para Smith e Ricardo ele está associado à estagnação e penúria, para Mill o mesmo se constitui num Estado de bem-estar, onde as necessidades materiais da sociedade já foram superadas. Ainda, para Mill, a feliz coincidência do término da acumulação com a superação das necessidades não significa um simples episódio técnico, mas tal situação estacionária da economia implica mudanças substâncias em sua própria natureza.

Estas são as principais questōes que se pretende analisar ao longo deste artigo. Seu objetivo não é apenas fazer uma análise das características e das causas de uma situação de estagnação no pensamento económico clássico. $O$ que se quer é principalmente analisar as circunstâncias teóricas em que surge a idéia de uma economia estacionária e realçar a importância da contribuição dos economistas clássicos para a compreensão da economia capitalista, de sua dinâmica e de suas contradiçōes internas.

Ao realçarmos a importância do tema, notamos ao mesmo tempo a carência de bibliografia específica sobre o assunto, motivo pelo qual 
sua abordagem se fará com base nas obras originais dos próprios autores, especialmente de Smith, Ricardo e Stuart Mill.

\section{SMITH E RICARDO: AS CAUSAS DO ESTADO ESTACIONÁRIO}

A concepção de Adam Smith sobre o crescimento econômico significa urn avanço importante em relação ao Mercantilismo e à Fisiocracia. Não há, efetivamente, nos autores mercantilistas a preocupação explícita com o crescimento econômico no sentido de um processo sustentado, motivo pelo qual não é possivel identificar nos mesmos algo que se possa chamar de teoria do crescimento. Sua concepção estática de riqueza, como acúmulo de metais, os impedia de fazê-los em suas circunstâncias históricas. Preocupados com a opulência e o poderio da Nação, procuraram eles colocar o crescimento ou sua estagnação como resultado muito mais das políticas estatais do que de algum fator de ordem econômica.

Já os fisiocratas desenvolveram idéias que, se não configuram uma teoria do crescimento propriamente dita, contêm elementos importantes para a sua formulação.

Quesnay, embora preso à noção de que todo o excedente resultava, em última análise, da produtividade da terra, colocou na acumulação do mesmo a possibilidade de um crescimento contínuo do produto nacional. A acumulação do excedente torna-se o elemento central do progresso. Seu consumo supérfluo, um fator de baixa acumulação e atraso.

Para Smith, a "Riqueza das Nações" depende do trabalho humano. Ela é produzida e não algo natural. $O$ progresso continuado da riqueza, este sim, possui seu "curso natural", que precisa ser respeitado. É connecida a passagem citada por E. Canaan na sua Introduçăo à Riqueza das Nações, onde Smith afirma que "pouco se requer para elevar um Estado da barbárie mais baixa, para o mais alto grau de opulência". O "curso natural" do progresso reside na descoberta e aplicação dos princípios e leis que comandam a atividade econômica capitalista. Daí a sua preocupação em descobrir essas leis "naturais" da economia, para mentêla num permanente "Estado progressivo".

No entanto, desde o inicio da sua obra principal, quando identifica as causas do crescimento com o contínuo aprimoramento das forças produtivas do trabalho e não com os fatores naturais, ele levanta a idéia de que o crescimento tem um término, ou seja, a idéia é de que isto é 
válido "enquanto durar este estado de coisas" (Smith, 1983, p. 36). Smith distingue um "país rico" de um "país progressista". O primeiro é aquele que já atingiu um elevado grau de riqueza e não pode mais crescer. O segundo é o país em que existe um incremento contínuo de riqueza.

O crescimento caminha inevitavelmente para um ponto de saturação que, entre outros fatores, se constitui na causa principal do aparecimento do Estado Estacionário. Para melhor entender a dinâmica desse processo concebido por Smith é necessário retornar à sua teoria do crescimento.

A teoria do crescimento econômico de Smith, como também a de Ricardo, representa a concepção de um movimento contraditório em direção ao Estado estacionário, como diz Deane:

O traço mais característico da Teoria clássica do crescimento foi que ela acabou visualizando o processo de crescimento como um inexorável movimento em direção a um Estado estacionário (Deane, 1980, p. 62).

O núcleo central da teoria do crescimento de Smith reside na articulação dinâmica entre divisão (produtividade) do trabalho, excedente e acumulação. A produtividade do trabalho é a causa geradora do excedente, que, uma vez poupado, tem sua acumulação garantida automaticamente. Uma maior acumulação, por sua vez, estimula a divisão-produtividade do trabalho, geradora de um ainda maior excedente.

Há, ainda, outros elementos que se articulam dinamicamente ao trinômio "acumulação de capital - produtividade do trabalho - geração de excedente", que são o crescimento populacional e a limitação dos recursos naturais. $\dot{E}$ com esses fatores que Smith concebe um mecanismo econômico auto-alimentado e em movimento para uma situação estacionária da economia e da sociedade.

O modelo de crescimento de Smith pode ser expresso, em seus elementos essenciais, pela equação a seguir:

\footnotetext{
$Y_{\mathrm{f}} \quad=(P / \overline{\mathrm{w}}) \mathrm{E}_{\mathrm{t}}-1$, onde

$Y_{t}=$ produto do ano corrente (trigo)

$\mathrm{P} \quad=$ produtividade do trabalho (quantidade do trigo produzida por trabalhadores) $=Y_{t} / L$, sendo $L=$ número de trabalhadores.

$\overline{\mathrm{w}} \quad=$ taxa de salário (quantidade de trigo insumido por trabalhador)

$E_{t-1}=$ excedente de produto (trigo) do ano anterior para ser investido $=L \bar{w}$.
} 
Nesses termos, para que o produto do ano corrente $\left(Y_{t}\right)$ seja maior que o do ano anterior $\left(Y_{t}-1\right)$, ou seja, para que haja crescimento econômico do país, é necessário que a produtividade do trabalho cresça mais que a taxa de salários. A concepção do processo de crescimento em termos de um produto agricola não significa que Smith tenha colocado sua primazia nesse setor. Embora tenha visualizado o "curso natu-

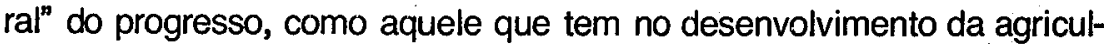
tura seus primeiros impulsos, não há dúvida de que, para Smith, o setor mais importante é o industrial, justamente porque ele possibilita uma maior divisão do trabalho e, por conseqüência, uma maior produtividade, um maior excedente e uma maior acumulação.

Desta forma, Smith fazia depender o crescimento econômico fundamentalmente de dois fatores: uma crescente produtividade do trabaIho e uma também crescente acumulação de capital, alimentada pelo excedente. A pedra angular do crescimento reside, eritão, na contínua acumulação de capital, associada a uma permanente melhoria das forças produtivas do trabalho. Esse processo de crescimento pode continuar enquanto o produto per capita crescer mais que o consumo per capita, o que garante um contínuo excedente, uma crescente demanda por mão-de-obra e, através dela, um contínuo crescimento populacional.

No interior desse mecanismo de crescimento existem dois vínculos cruciais, donde brotam também os limites ao crescimento e o próprio Estado estacionário.

O primeiro vínculo se dá entre a poupança e a acumulação. A acumulação depende da existência de um excedente que possa ser investido. Sem poupança não há acumulação, para Smith. Para isso, é importante a questão da distribuição do excedente. Se todo ele for absorvido pelo salário ou pela renda da terra, a fonte de acumulação seca.

$O$ outro vínculo crucial, neste modelo, se estabelece entre a acumulação e o crescimento populacional. Uma crescente acumulação é acompanhada por uma sempre maior demanda de mão-de-obra, da qual resultam melhores salários e, com eles, maiores estímulos ao aumento da população. As leis demograficas estão, assim, associadas às leis da acumulação, ou, nas palavras de Smith, "a demanda" de homens regula a produção de homens". O fator primordial do crescimento é, então, a acumulação de capital, na medida em que dela dependem tanto o crescimento da população e da produtividade, como o do excedente e do produto.

Smith concebe, assim, um verdadeiro mecanismo de crescimento que se auto-alimenta e adquire autonomia de movimento. Embora não 
deva ser esquecida a questão dos rendimentos decrescentes, associados à limitação dos recursos naturais e à não introduçāo do progresso técnico como variável endógena do modelo, o importante é que o processo de acumulação entendido por Smith se autonomiza e passa a criar limites intemos a si mesmo: a acumulação caminha para um ponto de saturação.

A idéia de que a acumulação de capital é um processo contraditório que se movimenta e se retrai, em função da taxa de lucro, é uma idéia central, tanto em Smith quanto em Ricardo. Neste, ela se encontra mais explícita e elaborada, dado o maior grau de formalização de sua teoria econômica. Mas em Smith, há passagens que a apontam com toda a clareza:

O aumento do capital, o qual faz subir os salários, tende a baixar o lucro. Quando o capital de muitos comerciantes ricos é aplicado no mesmo negócio, naturalmente sua concorréncia mútua tende a reduzir seus lucros; e quando há semelhante aumento de capital em todos os diversos ramos de negócio de uma mesma sociedade, a mesma concorrência produz necessariamente o mesmo efeito em todos eles (Smith, 1983, p. 109).

Em um pals que tivesse adquirido a riqueza compativel com a natureza de seu solo e clima e com sua localização, em relação a outros pafses, e que, portanto, não tivesse mais possibilidade de progredir (grifo nosso) mas, ao mesmo tempo, náo estivesse regredindo, aconteceria o seguinte: tanto os salários do trabalho, como os lucros do capital, seriam provavelmente baixos (...) Em um país saturado de capital (grifo nosso) em relaçáo a todos os negócios a transacionar, esse montante tăo alto de capital seria aplicado em todo e qualquer setor especffico que a extensáo do comércio, comportasse. Em conseqüência, a concorrência seria, em toda a parte, a máxima e o lucro comum do capital seria igualmente o mais baixo possivel. Em um país que tivesse atingido seu grau pleno de nqueza (grifo nosso) e no qual em todo o ramo especffico de negócios houvesse o volume máximo de capital (grifo nosso) que pudesse ser aplicado, tanto a taxa de lucro liquida quanto a taxa de juros seriam extremamente baixas (Idem, p. 114-15).

Embora Smith não explicite a forma pela qual o aumento do capital acumulado comprime os lucros (ele dá a entender apenas que seria através de uma queda dos preços), a idéia que queremos salientar é a da acumulação como um processo contraditório, ao mesmo tempo induzido e freado pelo comportamento dos lucros. Se, por um lado, o aumento de capital baixa os lucros, a sua diminuição os eleva, como diz Smith: "Um capital grande ... produz lucros pequenos ... e um capital re- 
duzido, lucros elevados. (. . .) uma diminuição do estoque do capital de uma sociedade ... assim como baixa os salários, aumenta os lucros do capital (Idem, p. 112-113). O Estado estacionário surge justamente nesta perspectiva de uma saturação de capital associada a uma queda dos lucros.

Esta também é a idéia básica de Ricardo, que pode ser expressa por uma formalização simplificada de seu modelo:

$$
r=\frac{Y_{t}-\bar{w} L}{\bar{w} L}=\frac{Y_{t} \cdot 1}{L \cdot \bar{w}}-1=\frac{P}{\bar{w}}-1
$$

Onde:

$$
\begin{aligned}
& r=\text { taxa de lucro determinada na terra marginal, onde } \\
& \mathrm{Y}_{\mathrm{t}} \quad=\text { quantidade de trigo produzida na terra marginal; } \\
& \mathrm{L} \quad=\text { quantidade de trabalho utilizado para produzir } Y_{\mathrm{t}} \text { na } \\
& P=Y_{t} / L=\text { produtividade do trabalho ou a quantidade de trigo } \\
& \overline{\mathrm{w}} \quad=\text { taxa de salário, ou seja, a quantidade de trigo con- } \\
& Y_{t}-\bar{w} L=\text { lucro na margem extensiva. }
\end{aligned}
$$

Neste modelo, se o salário for constante, ao nivel da subsistência, como afirma a teoria clássica do salário, e se a produtividade " $p$ " for decrescente, em função da expansão do cultivo de trigo em terras menos férteis, existe uma tendência de a taxa de lucro cair. Como o motivo da acumulação é o lucro e, sendo este cada vez menor, sua queda progressiva desestimula a acumulação e gera a perspectiva de um Estado estacionário, à medida que a produtividade "p" for caindo. Pela equação, quando a produtividade do trabalho for igual à taxa de salário $(p=\bar{w})$, - lucro será igual a zero $(r=0)$. Este momento pode ser retardado pelä importação livre de alimentos, como diz textualmente Ricardo:

Deixemos que estes (...) sejam importados do estrangeiro em troca de bens manufaturados e será diffcil determinar o limite em que deixareis de acumular riqueza e obter lucro com sua aplicação (Works and Correspondence of Ricardo, apud Dobb, 1977, p. 117). 
Da mesma forma que a importação de alimentos, a queda dos lucros pode ser detida de tempos em tempos, pelos surtos de inovação técnica. No entanto, seus efeitos são passageiros, pois Ricardo não concebia a inovação técnica como um processo contínuo, nem tampouco como uma variável endógena ao modelo, a perspectiva do Estado estacionário é inevitável. Na realidade, a estagnação se concretiza muito antes de $p$ igualar a $w$, pois a acumulação ter-se-á interrompido muito antes desse momento, devido à falta de estímulo provocada pelas baixas de lucro. Nas palavras de Ricardo:

A tendência natural dos lucros, portanto, é diminuir, pois, como o desenvolvimento da sociedade $e$ da riqueza, a quantidade adicional de alimentos requerida se obtém com sacriffic de mais e mais trabalho. Essa tendência, como se os lucros obedecessem à lei da gravidade, é felizmente contida, a intervalos que se repetem, pelos aperfeicoamentos das maquinarias usadas na produção dos gêneros de primeira necessidade, assim como pela descoberta das ciências da agricultura, que nos permitem prescindir de uma parcela do trabalho antes necessário e, portanto, reduzir para o trabalhador o preço daqueles bens. $O$ aumento do preço de tais bens é, entretanto, limitado, pois, quando os salários equivalessem às receitas totais do arrendatário, a acumulação terminaria, uma vez que nenhum capital obteria lucro, não haveria nenhuma demanda adicional de trabalho e, conseqüentemente, a população teria atingido seu ponto mais elevado. De fato, bem antes dessa fase, a baixlssima taxa de lucro teria detido toda a acumulaçáo e quase todo o produto do pals, após o pagamento dos trabalhadores, pertenceria aos propretários de terra e aos cobradores de d/zimos e impostos (Ricardo, 1982, p. 97).

O Estado estacionário é aqui o destino último dessa tendência de lucros a diminuirem.

Embora, como afirma Dobb (1977, p. 116), Ricardo colocasse o Estado estacionário no contexto das "Leis dos Pobres", devido à tendência da população crescer mais que a acumulação, podemos pensar que a maior demanda por alimentos poderia ser provocada não necessariamente pelo crescimento populacional, mas pelo aumento da própria acumulação. Teriamos, então, interiorizado no modelo a causa da queda dos lucros.

Queremos sugerir aqui que existem suficientes indicações, tanto em Smith como em Ricardo, de que o movimento da acumulação, uma vez iniciado, vai ganhando autonomia e independência de seus fatores iniciais, a tal ponto que sua continuidade, ou não, passa a depender dele mesmo. 
Se nos limitarmos aos elementos formais dos modelos, e o de Ricardo principalmente, parece claro que o limite do crescimento seja dado pelos rendimentos decrescentes da agricultura de alimentos, ou seja, que o crescimento prosseguirá impulsionado pela produtividade crescente do trabalho, associado a uma também crescente acumulação de capital, enquanto houver recursos naturais para alimentar uma crescente população, que deles depende.

No entanto, é preciso ir além dos alementos formais dos modelos. Um modelo não passa de um instrumental utilizado para captar e transmitir idéias aproximadas da realidade. $E$ a idéia básica que Smith $e$ Ricardo transmitem em sua teoria da acumulação e do crescimento parece ser a de que estes são processos contraditórios que corroem suas próprias energias à medida que avançam em direção ao Estado estacionário.

Pela lógica dos modelos clássicos analisados, o Estado estacionário, uma vez atingido, não precisa necessariamente ser permanente, pois o crescimento poderá ser retomado, de tempos em tempos, por surtos de progresso técnico, que atuarão sobre a produtividáde do trabalho. Mas, como a inovação técnica é considerada um dado e não uma variável, ou seja, o capital é considerado como complementar ao trabalho e não como seu substituto, os efeitos de cada inovação se esgotam rapidamente na medida em que o crescimento, cada vez retomado, reativará todo o mecanismo que reconduz a economia à situação estacionária. Assim, nas palavras de Deane: "A dinâmica clássica era, portanto, essencialmente a teoria da progressão para o Estado estacionário". (Deane, 1980, p. 63).

\section{STUART MILL: O ESTADO ESTACIONÁRIO ÓTIMO}

As questões básicas colocadas por Stuart Mill referem-se ao sentido das leis de movimento da economia. No início do capítulo 6 , ele formula uma série de perguntas, todas elas marcadas pela idéia de que o progresso material não é limitado. Para onde tende a sociedade e o progresso? Quando o progresso chega ao fim, em que condições terá deixado a sociedade?

Os economistas deverm sempre ter visto, mais ou menos distintamente, que o aumento da riqueza não é limitado; que no final do Estado chamado progressivo, há o Estado estacionário; que todo o progresso da 
riqueza não é mais do que um adiamento do advento desse último e que, a cada passo à frente, mais nos aproximamos dele. Podemos agora reconhecer que essa meta final está sempre bastante proxima, para que se possa vé-la claramente; que estamos sempre em suas fronteiras $e$, se ainda não a alcançarmos, é porque a própria meta foge para a nossa frente. Os palses mais ricos e mais prosperos cedo chegariam ao Estado estacionário, se não se realizassem novos melhoramentos nas partes produtivas e, se fosse interrompida a emigração do capital de tais regióes para regióes não cultivadas ou pouco cultivadas da terra (Mill, Princípios de Economia Polfica, apud Napoleoni, 1982, p. 145).

Destacamos alguns pontos importantes contidos nesta citação. Primeiro, a idéia clara de que o progresso não é ilimitado. Por outro lado, seus limites não são fixos, são móveis. Seu movimento é determinado pelas mesmas forças que impulsionam o crescimento. Mesmo assim, há uma certeza: o ponto de chegada, mesmo se deslocando para frente, à medida que dele nos aproximamos, está sempre mais próximo. Esta aproximação sucessiva permite que se conheçam as características do Estado estacionário.

Para Mill, a transformação do Estado progressivo em Estado estacionário estabelece diferenças em comparação com a perspectiva de Smith e Ricardo. Para estes últimos, mas especialmente para Smith, que vive nas primeiras décadas da Revolução Industrial, o fim do crescimento era principalmente uma conseqüência lógica de seu modelo. Mill vive uma situação econômica já bem mais amadurecida, por isso o Estado estacionário era, para ele, uma realidade bem mais próxima. Mas a principal diferença não é esta e sim a da natureza do próprio Estado estacionário. Para Smith e Ricardo ele significa estagnação e penúria. Para Mill ele coincide com uma situação de abundância e bemestar para a sociedade. Voltaremos a esta questão importante mais à frente.

E no livro IV de seus Principios que Mill analisa a questão. Nos capitulos 4 e 5, ele discute a tendência dos lucros para uma taxa minima e suas conseqüências. No capítulo 6, descreve as características do Estado estacionário propriamente dito. Procuraremos aqui fazer uma análise do seu pensamento com base nos três capítulos acima referidos.

Mill observa inicialmente que existe uma certa taxa de lucro, abaixo da qual não há motivo suficiente para acumular com a finalidade de valorizar o capital. Esta taxa deve compensar a obstinência e oferecer uma garantia suficiente contra os riscos do investimento. Ela varia in- 
versämente com o progresso da sociedade, pois este mesmo progresso tende a reduzir os riscos dos investimentos. $O$ certo é que esse minimo de lucros, seja mais alto ou mais baixo, existe sempre e, uma vez alcançado, impede qualquer aumento posterior da acumulação: "O país alcançou, então, - diz Mill - aquele estado que os economistas chamam de estacionário" (Mill, op. cit., apud Napoleoni, 1982, p. 129).

Quando a taxa de lucro chega a esse mínimo, que marca a passagem para o Estado estacionário? O próprio Mill responde:

Quando um pals goza, por muito tempo, de uma ampla produçăo e de uma alta renda média, de onde possa extrair a poupança; e quando, por isso, existem, ha muito tempo, os meios para um forte aumento anual de capital ...; quando isso ocorre é sinal de que naquele pals a taxa de lucro esta geralmente bem próxima do mínimo e que, portanto, o pals está para ingressar no Estado estacionário (Mill, op. cit, apud Napoleoni, 1982, p. 129).

Embora Mill não acredite que os grandes paises da Europa estivessem prestes a atingir tal Estado, afirma que bastaria bem pouco tempo para reduzir o lucro a um mínimo, caso o capital continuasse a aumentar no mesmo ritmo em que vinha aumentando, se esse limite mesmo não se deslocasse continuamente. É muito interessante a análise que Mill faz da relação dinâmica entre o avanço da acumulação e o deslocamento desse mínimo de lucros, mediante a atuação de fatores contrapostos à queda dos lucros. Entre estes fatores, como a exportação de capital para investimento no exterior, as despesas improdutivas do governo, a desvalorização do capital, mediante a falência de empresas, as novas invençōes industriais, um deles merece destaque: a destruição de capital durante as crises que "produzem um temporário aumento dos juros e do lucro e dão lugar as novas acumulaçōes; e o ciclo recomeça" (Idem, p. 132).

Da mesma forma, os melhoramentos da produção, já mencionados, são um fator importante no deslocamento do limite mínimo dos lucros, pela ampliação das fronteiras internas da acumulação que provocam, pois eles "tendem, de algum modo, a ampliar o intervalo que deve ocorrer antes que se chegue ao Estado estacionário" (Idem, p. 134). Mill afirma que a abolição das "Leis do trigo" contribuiu para abrir um longo período de crescimento, sem diminuir a taxa de lucro, ao permitir a importação de alimentos baratos do estrangeiro. Finalmente, a emigração de capital para as colônias atua duplamente no sentido de impedir a queda dos lucros: por um lado, ao tornar o capital mais escasso internamente e, por outro, ao ser aplicado na produçāo de alimentos mais 
baratos para o país de origem do capital. Esse fator desempenhou um papel historicamente importante para o seu próprio país:

Creio que, por muitos anos, foi essa uma das principais causas do estancamento da queda dos lucros na Inglaterra (. . .). Enquanto existirem palses velhos, nos quais o capital cresce rapidamente, e palses novos, nos quais o lucro é ainda alto, os lucros nos palses velhos não cairão até o ponto de interromperem a acumulação (ldem, p. 136-37).

Contrariamente à preocupação de Smith no sentido de estimular a poupança e de valorizar a frugalidade, por serem pré-condição ao aumento de um capital ainda escasso naquele momento histórico, a preocupação de Mill reside em tornar esse capital escasso, com forma de dar continuidade ao progresso da acumulação. Por isso, argumenta que uma diminuição de capital, através das mais variadas formas, inclusive dos gastos governamentais improdutivos, não empobrece o país, nem prejudica a acumulação, mas, ao contrário, a reestimula, pela elevação dos lucros:

... a náo ser que uma grande parte do aumento anual do capital seja periodicamente destrulda ou exportada para ser investida no exterior, $o$ pals cedo alcançaria o ponto no qual toda a acumulação ulterior cessaria (. . .). Mas nos palses ricos, populosos e bem cultivados, não é o capital que faz falta e sim a terra fértil. (. . . . . . cada milhão que é gasto deixa lugar a um outro milhão que será poupado antes que se alcance o ponto de saturaçăo (Idem, p. 139-40).

Se o Estado estacionário é uma necessidade histórica produzida pelas próprias forças promotoras do crescimento, cabe agora analisar a natureza que lhe atribui Mill. Smith e Ricardo o haviam identificado como um estado de estagnação e pobreza. Com efeito, afirmou Smith que:

... a condiçáo dos trabalhadores pobres parece ser a mais feliz e a mais tranqüila no Estado de progresso, em que a sociedade avança para a maior riqueza e não no estado em que já conseguiu sua plena riqueza. $A$ condição do trabalhador é dura na situação estacionária e miserável, quando há declínio económico da naçáo. O Estado de progresso é, na realidade, o Estado desejâvel para todas as classes sociais, ao passo que a situação estacionária è a inércia e o Estado de declínio é a melancolia (Smith, op. cit., p. 103).

A posição de Mill é diferente, pois ele faz coincidir o término da acumulação com ó Estado de bem-estar, embora não explique como se 
dá essa tranșição:

Portanto, não posso considerar o Estado estacionário do capital e da riqueza com a evidente aversão que, em face dele, geralmente se manifesta entre os economistas da velha escola. Estou propenso a crer que, no conjunto, ele representa um considerável melhoramento com relação às nossas condiçóes atuais. (. . .). Talvez seja supérfluo observar que uma condiçáo estacionária do capital e da população não implica, de modo algum, um Estado estacionário do progresso humano (Mill, op. cito, apud Napoleoni, 1982, p. 147 e 149).

Mill expressa aqui a consciência de que o progresso material, nas condições capitalistas, não objetiva beneficiar a todas as classes sociais. Reprova aquilo que constitui a natureza da própria economia capitalista: acumular por acumular, crescer por crecer: "Confesso que nâo me agrada o ideal da vida sustentado pelos que pensam que o estado normal dos homens seja uma luta para seguir em frente" (Idem, p. 147). Muito mais aconselhável - diz ele - seria que, enquanto a riqueza de poder e, enquanto enriquecer o mais possivel for objeto de ambição universal, o caminho para alcançar riqueza esteja aberto a todos. A situação ideal seria aquela em que não houvesse mais pobres, nem ricos ávidos por maior riqueza. "Tão somente nos paises atrasados é que uma maior produção é ainda hoje uma meta importante, mas nos desenvolvidos, o que é necessário, hoje, é uma melhor distribuição (Idem, p. 148).

Espera Mill que o término do incentivo a acumular não só coincida com a abundância material para todos, mas também com transformaçōes estruturais no caráter da economia, a tal ponto que a sociedade estacionária seja mais igualitária. Desse processo resultaria uma sociedade com essas caracteristicas:

Uma classe trabalhadora bem paga e abundante; ausência de fortunas enormes, salvo aquelas ganhas e acumuladas no curso de uma só vida e uma categoria de pessoas bem mais numerosa que hoje, năo apenas liberta dos esforços mais pesados, mas também com um tempo livre suficiente para poder se dedicar às coisas amenas da vida . . . (. . .). Essa condição da sociedade, tão preferivel à atual, náo apenas é perfeitamente compativel com o Estado estacionário, mas é, inclusive, mais consentânea com ele que com qualquer outro estado (ldem, p. 148 e 149).

É importante notar, no entando, como faz Napoleoni, que não há em Mill nenhuma demonstração de que o tempo gasto pela taxa de lucro para chegar a zero coincida com o tempo necessário para tomar a 
acumulação supérflua, do ponto de vista da satisfação das necessidades. Por outro lado, mesmo admitindo que o Estado estacionário coincida com a superação das necessidades materiais, a passagem de uma para a outra situação não é simples episódio técnico, mas envolve mudanças qualitativas na própria natureza da economia capitalista, pois esta não seria mais movida pela ambição de acumular por acumular. $O$ Estado estacionário seria, então, para Mill, a superação do capitalismo.

\section{CONCLUSÃO}

Como conclusão, vamos retomar as principais questões colocadas no decorrer do trabalho.

Constitui, sem dúvida, um grande mérito dos economistas clássicos terem-se colocado como problema investigar as leis de movimento da economia e, entre elas, a que determina o comportamento dos lucros, questão-chave para se entender o processo de acumulação de capital. Esta é representada como um movimento contraditório e autônomo a caminho de um ponto de saturação, ponto que não é fixo, mas móvel, uma perspectiva cujo horizonte se desloca à medida que dele nos aproximamos.

A concepção clássica de economia é uma concepção dinâmica. As mesmas forças que impulsionaram seu crescimento, geram efeitos contrários, os quais se constituem em freios à continuidade da acumulação. Dessa forma, o Estado estacionário não é outra coisa que o próprio Estado progressivo levado às últimas conseqüências.

O principal problema da concepção de Smith e Ricardo consiste em não terem eles integrado o progresso técnico como variável endógena de seus modelos. A inovação técnica, apesar de ser seguidamente mencionada ao longo de suas obras, como sendo capaz de impedir, de tempos em tempos, a queda dos lucros, não é considerada como uma ação permanente desencadeada pela mesma concorrência intercapitalista, que provoca a queda dos lucros. Se assim tivessem pensado, poderiam ter entendido que $o$ aumento do estoque de capital pode não ser acompanhado pelo aumento proporcional de seu valor e, por conseqüência, não provocar uma queda dos lucros, já que é produzido em novas condições técnicas. Apesar disso, Mill não deixa de realçar, corretamente, a função das crises económicas, das guerras, da exportação de capital e da especulação destrutiva, como fatores que, ao tornarem o capital escasso, historicamente atuaram no sentido de impedir a queda 
dos lucros e de deslocar o limite do crescimento e a perspectiva do Estado estacionário.

Finalmente, a questão da natureza da situação estacionária, colocada por Mill. Por um lado, conceber, como ele o fez, que a produção capitalista possa ter continuidade depois que cessarem os motivos à acumulação, significa uma supressão mecânica do capitalismo, uma vez que ela encontra em si mesma sua razão de ser. Por outro, imaginar que esta transformação qualitativa possa decorrer de um "transbordamento" do acúmulo quantitativo, não deixa de ser também uma conclusão lógica.

Esta transição dó Estado progressivo para o Estado estacionário não precisa ser concebida mecanicamente, uma vez que pode ser mediada pelas forças sociais e pela decisão política, o que, sem dúvida, estaria mais de acordo com uma visão da história que é resultado de forças sociais e não de forças mecânicas.

\section{BIBLIOGRAFIA}

1. DEANE, Phyllis. A Evolução das Idéias Econômicas. Rio de Janeiro, Zahar, 1980.

2. DOBB, Maurice. Teorias do Valor e Distribuição Desde Adam Smith. Lisboa, Presença, 1977.

3. MILL, John Stuart. Princípios de Economia Política. São Paulo, Abril Cultural, 1983. 2 v.

4. NAPOLEONI, Cláudio. O Futuro do Capitalismo. Rio de Janeiro, Graal, 1982.

5. RICARDO, David. Princípios de Economia Política e Tributação. São Paulo, Abril Cultural, 1982.

6. SMITH, Adam. A Riqueza das Nações. São Paulo, Abril Cultural, 1983. 2 v.

THE "STATIONARY STATE" IN CLASSICAL ECONOMICS

\section{ABSTRACT}

This paper intends to analyze the idea of the "Stationary State" in the sphere of classical economics, particularly in the works of Smith, Ricardo, and Stuart Mill. These authors focused their attention on the question of long run economic growth, and on the ever present possibility that this growth might be interrupted. The "Stationary State" follows from the logic itself-of the classical conception of growth: the progressive state runs its course, necessarily, into the "Stationary State". 